\title{
FEIÇÕES MORFOLÓGICAS NO BAIXO CURSO DO RIO SEPOTUBA ENTRE A FAZENDA PORTO DO CAMPO E AFAZENDA AJUSTA CONTA, SUDOESTE DE MATO-GROSSO
}

\author{
Vanilda Soares Prudêncio ${ }^{(a)}$,Célia Alves de Souza ${ }^{\text {b) }}$,Evanil Rocha ${ }^{\text {c) }}$,Carolina da Costa \\ Tavares $^{(\mathrm{d})}$
}

(a) Departamento Geografia UNEMAT, e-mail:vanildaster96@ gmail.com
(b) Departamento Geografia UNEMAT, e-mail: celiaalvesgeo@globo.com
${ }^{(c)}$ Departamento Geografia UNEMAT, e-mail: evanilmt030@ hotmail.com
${ }^{(\mathrm{d})}$ Departamento Geografia UNEMAT, e-mail: $\underline{\text { carolina tavares 5@ } 5 \text { hotmail.com }}$

EIXO:BACIAS HIDROGRÁFICAS E RECURSOS HÍDRICOS: ANÁLISES, PLANEJAMENTO E GESTÃO

\section{Resumo}

\begin{abstract}
A pesquisa foi desenvolvida no baixo curso do Rio Sepotuba. O estudo teve como objetivo identificar as alterações no uso do solo e nas características morfológicas no baixo curso do rio Sepotuba entre a Fazenda Porto do Campo e a Fazenda Ajusta Conta. Realizou pesquisas bibliográficas para suporte teórico-conceitual do estudo emapeamento com uso de imagem de satélite e as ferramentas do software ArcGis 9.3.Os dados referente as alterações espaço-temporal entre 1986 a 2016, mostraram que houve diminuição das áreas preservadas e aumento da atividade antrópica. Registrou aumento e diminuição na dimensão das lagoas, surgimento e desaparecimento de outras lagoas.
\end{abstract}

Palavras-Chave: Ambientes Fluviais; Planície de Inundação; Ação Antrópica.

\section{INTRODUÇÃO}

A bacia hidrográfica ou de drenagem é uma área da superfície terrestre, drenada por um rio principal e seus tributários. Ela representa a área de captação que fez convergir o escoamento para um único ponto de saída, o exutório. A bacia de drenagem é delimitada pelos divisores de água, a partir da definição de um dado ponto de saída (FLORENZANO, 2008).

A bacia hidrográfica do rio Sepotuba possui uma área de $9.844,5051 \mathrm{~km}^{2}$ (SERIGATTO, 2006). O rio Sepotuba é afluente da margem direita do Paraguai, sendo um dos mais importantes afluentes do BAP( Bacia do Alto Paraguai), juntamente com o Cabaçal e Jauru.

O trecho em estudo corresponde ao padrão de canal meandrante. Os canais meandrante são encontrados nos rios que percorrem regiões quentes e úmidas em terrenos planos e possuem curvas sinuosas. O processo de meandramento pode apresentar ajuste entre as variáveis hidrológicas, inclusive a carga detrítica e a litologia, em que se instala o curso d'água (CHRISTOFOLETTI, 1980).

De acordo com Souza e Cunha (2012), a dinâmica fluvial de uma bacia hidrográfica reflete as interrelações existentes entre as características dos elementos ambientais, tais como; clima, geologia, 
cobertura vegetal, geomorfologia, solo e, as formas de uso e ocupação da terra. Estes elementos juntos determinam o regime hidrológico através da quantidade de água e do tipo de sedimentos fornecidos à bacia.

Cunha (1998) considera que a bacia hidrográfica é uma unidade geomorfológica muito importante por agrupar e interagir vários fatores, tais como: bióticos, abióticos, econômicos e sociais. As bacias hidrográficas interagem numa visão de conjunto, ressaltando-se as condições naturais e as atividades humanas nelas desenvolvidas. Intervenções expressivas, principalmente de origem antrópica em qualquer parte de uma bacia podem gerar alterações, cujos impactos serão transferidos a jusante, influenciando no fluxo energético e na dinâmica fluvial.

O estudo teve como objetivo identificar as alterações no uso do solo e nas características morfológicas no baixo curso do rio Sepotuba entre a Fazenda Porto do Campo e a Fazenda Ajusta Conta, nos anos de 1986 e 2016.

\section{MATERIAL E MÉTODOS}

\section{1 Área de estudo}

A área de estudo corresponde ao trecho do baixo curso do rio Sepotuba entre a Fazenda Porto do Campo e a Fazenda Ajusta Conta na região Sudoeste de Mato Grosso, com 14km de extensão. Encontra-se entre as coordenadas geográficas $15^{\circ} 42^{\prime} 36.46^{\prime \prime}-15^{\circ} 44^{\prime} 33.51^{\prime \prime}$ Latitude Sul e57³9' 04.51 ” $-57^{\circ} 42$ ' 37.49” Longitude Oeste (Figura 1). 


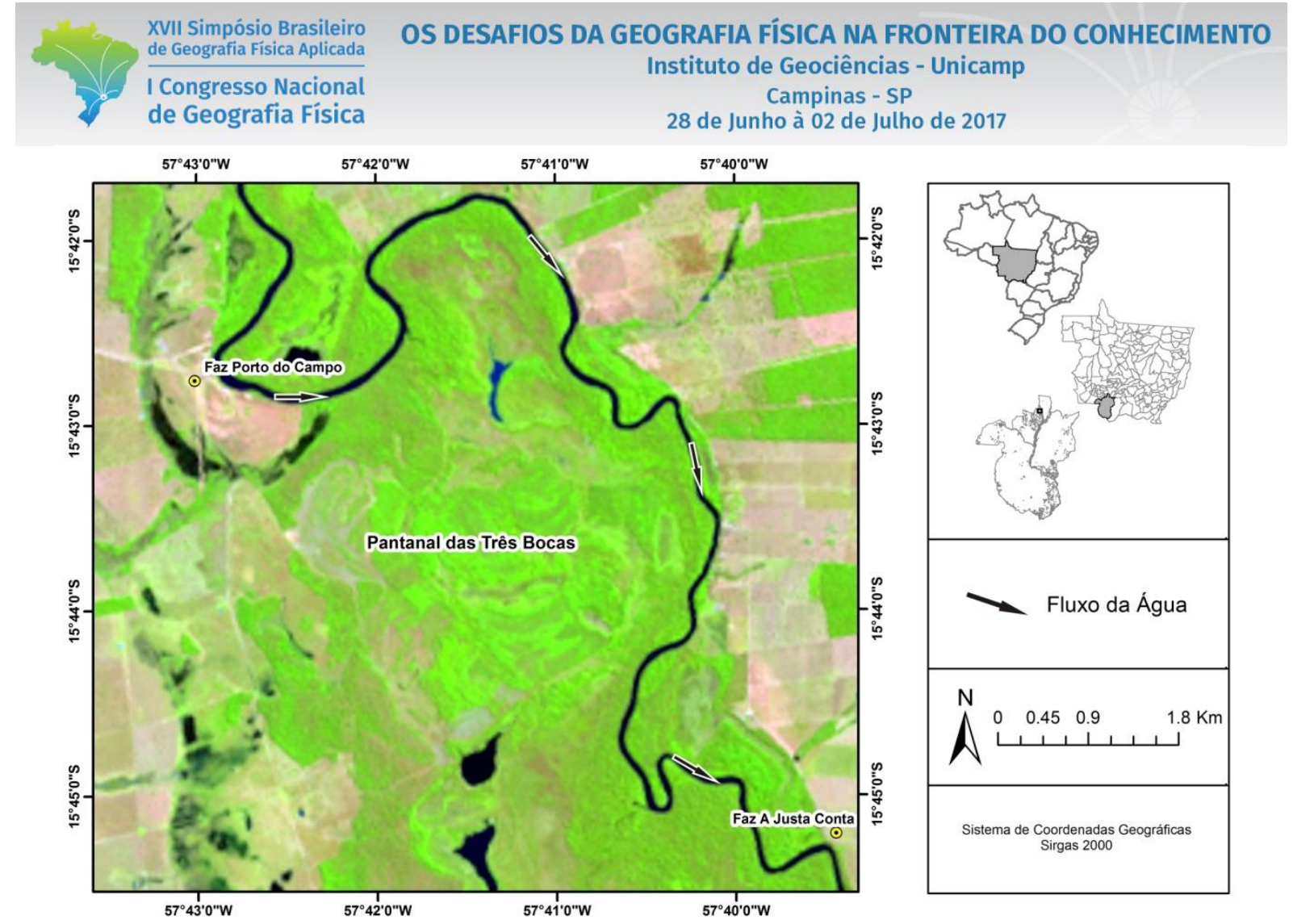

Figura 1: Localização da área de estudo

A bacia hidrográfica do rio Sepotuba drena $11.460 \mathrm{~km}^{2}$, com vales estreitos e cobertos por vegetação densa. A planície de inundação é limitada, mesmo no baixo vale. Próximo à foz, a área de inundação é extensa com vários meandros abandonados (CARVALHO, 1986).

\subsection{Procedimentos metodológicos}

Para elaboração dos mapas foi utilizado imagens de satélite LANDSAT 8 OLI com 30 metros de resolução espacial, posteriormente a imagem passou pela composição de bandas 4, 5 e 6 RGB em falsa cor, logo após redimensionado rasterpara 15 metros de resolução pela função Pan Sharpen através da banda 8(Pan), inserido arquivo vetorial sobre o mesmo delimitando a área de estudo, recortando o rasteratravés da função ExtractbyMask. Confeccionado layout do mapa.

Para fazer os mapas temporais usou Imagens/rasterdos satélites LandSat 5 TM e LandSat 8 OLI. Criado arquivo vetorial, constituindo classes de análises e classificado por cada feição sobre a área de estudo, posteriormente a vetorização, calculado a área dos polígonos em quilômetros quadrados. $\mathrm{O}$ mesmo processo segue-se de forma semelhando a todas as imagens. Confeccionando layout do mapa, seguindo normativas cartográficas. 
XVII Simpósio Brasileiro

de Geografia Fisica Aplicada

I Congresso Nacional

de Geografia Física

\section{OS DESAFIOS DA GEOGRAFIA FÍSICA NA FRONTEIRA DO CONHECIMENTO \\ Instituto de Geociências - Unicamp \\ Campinas - SP \\ 28 de Junho à 02 de Julho de 2017}

\section{RESULTADO E DISCUSSÕES}

A área de estudo corresponde um trecho do rio Sepotuba, o canal possui padrão meandrante. Na margem esquerda possui um nível mais alto devido a ocorrência de terraço, constituído por material aluvionar mais antigo, na margem direita a baixa declividade topográfica favoreceu a ocorrência de planície de inundação, denominado regional como Pantanal Três boca.

O Pantanal Três Boca corresponde a uma área de inundação temporária devida sua baixa declividade, recebe água e sedimentos, resultante do transbordamento do rio Sepotuba, registra a presença de lagoas de formas circulares ou semicirculares. A dinâmica de cheia do rio Sepotuba provoca a remoção e a acumulação na planície (diques e cordões marginais) e lagoas.

As categorias mapeadas foram: cobertura vegetal, planície de inundação e lagoas. Em 1986 a categoria cobertura vegetal preservada possuía $15.37675 \mathrm{~km}^{2}$ diminuído para3,635508 $\mathrm{km}^{2}$ e a planície de inundação era $41.189 \mathrm{~km}^{2}$ reduziu para $39.686 \mathrm{~km}^{2}$ ( Figura 2). A categoria cobertura vegetal que sofreu maior alteração a mata ciliar foi substituída por pastagem. No mapeamento de 2016 foi registrado uma nova categoria, a atividade antrópica que passou abranger uma extensão de 33.368 $\mathrm{km}^{2}$.

Foram identificadas,na margem direita do rio Sepotuba, 18 lagoas em 1986. Em 2016 registrou o desaparecimento de 9 lagoas e surgimento de 13 lagoas, sendo 12 na margem direita e 1 na margem esquerda (figura 2). As lagoas são porções de água circundada de solo, podendo ser perenes ou não (LIMA, et. al.2014).
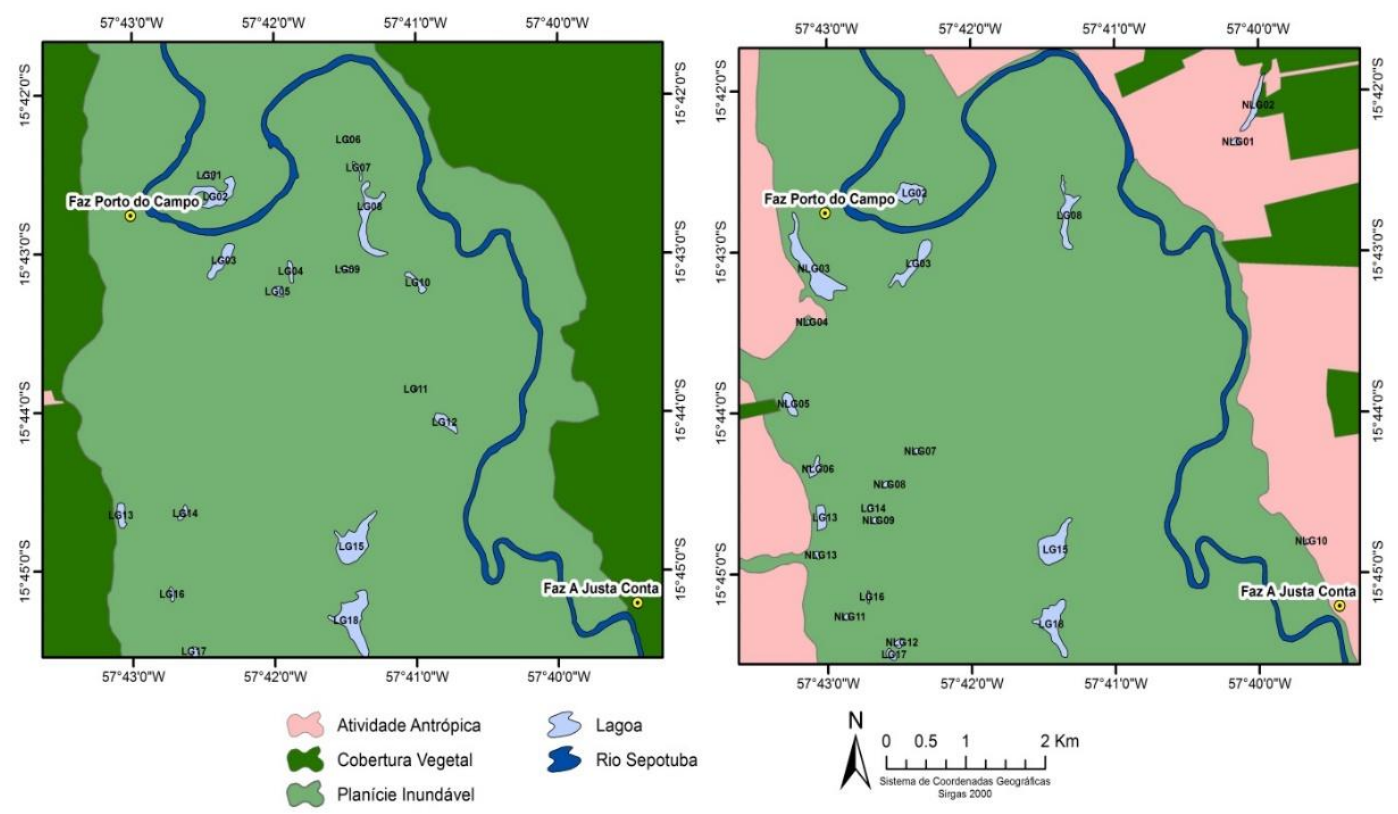

Figura2: Distribuição espacial das categorias estudadas entre a Fazenda Porto do Campo e a Fazenda Ajusta Conta. 


\section{CONSIDERAÇÕES FINAIS}

O estudo permitiu indentificação de várias lagoas que no decorrer dos trinta anos algumas desapareceram ou outras surgiram, mudaram também sua dimensão. Parte da cobertura vegetal foi retirada para introdução da pecuária.

\section{REFERÊNCIAS BIBLIOGRÁFICAS}

CHRISTOFOLETTI,A. Geomorfologia. 2. Ed. São Paulo: Edgar. BLUCHLER.188pp. 1980.

CUNHA, S. B. Bacias hidrográficas. In: CUNHA, S. B.; GUERRA, A. J. T. (Orgs.). Geomorfologia do Brasil. Rio de Janeiro: Bertrand do Brasil, 1998. p. 229 - 265.

FLORENZANO,T,G; Geomorfologia: conceito e tecnologias atuais/ Teresa Gallotti Florenzano, (org.). Oficina de texto 2008.

LIMA,T. SILVA,C. SOUZA,C. LEANDRO,G. Feições, Morfologia e Sedimentação de fundo e suspensão do Rio Paraguai no pantanal de Cáceres- Mato Grosso, no trecho entre a Baía do Ponto Certo á Foz do Corrego Jacobina..Revista Geonorte. V.10, n.1, p.391-396, 2014.

SERIGATTO, E, M. Delimitação Automatica das Areas de Preservação Permanente e Indentificação dos Conflitos de Uso do Terra na Bacia Hidrografica do Rio Sepotuba. 2006. 205f. Tese (Doutorado em Ciência Florestal) - Universidade Federal De Viçosa, Minas Gerais, 2006.

SOUZA, C. A.; CUNHA, S. B. Feições morfológicas do rio Paraguai e sua dinâmica entre a cidade de Cáceres e a Estação Ecológica da Ilha de Taiamã-MT. In: SOUZA, C. A. (Org.). Bacia hidrográfica do rio Paraguai MT: dinâmica das águas, uso, ocupação e degradação ambiental. São Carlos-SP: ed. Cubo, 2012. p. 81 - 94. 